\title{
Sentiment Analysis Using Twitter Data Regarding BPJS Cost Increase and Its Effect on Health Sector Stock Prices
}

\author{
${ }^{1}$ Evita Dyah Wardhani, ${ }^{2}$ Arya Wahyu Nugroho, ${ }^{3}$ Ayufi Reyza Zakaria, \\ ${ }^{4}$ Satria Kurnia Areka, ${ }^{5}$ Arya Damar Prakasa, ${ }^{6}$ Rani Nooraeni \\ $1,2,3,4,5,6$ STIS, Polytechnic of Statistics \\ Email: ${ }^{1}$ evitadyahw@gmail.com, ${ }^{2}$ aryawahyu2022@gmail.com, ${ }^{3}$ ayufireyza@gmail.com, \\ ${ }^{4}$ satria.areka@gmail.com, ${ }^{5}$ aryadamarprakasa@gmail.com, ${ }^{6}$ raninoor@stis.ac.id
}

\begin{tabular}{l}
\hline \hline Article Info \\
\hline Article history: \\
Received October $25^{\text {th }}, 2019$ \\
Revised December $13^{\text {th }}, 2019$ \\
Accepted February $15^{\text {th }}, 2020$ \\
\\
\hline Keyword: \\
Healty \\
Sentiment \\
Twitter \\
Stock
\end{tabular}

Corresponding Author:

Rani Nooraeni

Politeknik Statistika STIS

Jalan Otto Iskandardinata no 64C, 13330

Email: raninoor@stis.ac.id

\begin{abstract}
News about BPJS costs that will increase by $200 \%$ has provided various responses in the community. One of the social media used by the public in responding to something is Twitter. This research is used to see public sentiment on Twitter about BPJS cost policies. In addition, the impact of this sentiment will also be seen in health sector stock prices. The analysis used is descriptive analysis and inference analysis. Descriptive analysis is used to see a general picture of community sentiment and inference analysis is used to see the impact of community sentiment on the price of health stocks, namely Indo Farma and Kimia Farma. The results of this study indicate that public sentiment towards rising BPJS costs is dominated by negative sentiment. And for the level of tendency that has been processed through binary logistic regression analysis shows that negative sentiment will make Kimia Farma shares will go down while positive sentiment will make Kimia Farma shares will go up. As for the IndoFarma stock, positive and negative sentiments from IndoFarma shares will tend to fall.
\end{abstract}

Copyright (C) 2020 Puzzle Research Data Technology

DOI: http://dx.doi.org/10.24014/ijaidm.v3i1.8245

\section{PENDAHULUAN}

Dewasa ini, kesehatan menjadi salah satu kebutuhan yang sangat penting. Dalam menyelesaikan masalah kesehatan di negara, pemerintah memberlakukan kebijakan mengenai Badan Penyelenggara Jaminan Sosial pada tahun 2014. Kebijakan ini diatur dalam UU No 40 Tahun 2004 tentang sistem jaminan sosial nasional dan UU no 24 Tahun 2011 tentang Badan Penyelenggara Jaminan Sosial. Undang-undang tersebut mengamanahkan bahwa setiap warga Negara Indonesia wajib mengikuti program BPJS. Akan tetapi, walaupun sudah diatur di dalam undang-undang, pada kenyataannya program BPJS ini masih terkendala, salah satunya adalah penerimaan yang defisit akibat tunggakan iuran masyarakat. Sehingga untuk mengatasi masalah tersebut, pemerintah akan menaikkan tarif BPJS sebesar 2x lipat.

Rencana ini pertama kali diumumkan oleh Dewan Jaminan Sosial Nasional (DJSN) pada Hari Selasa, 13 Agustus 2019. Sejak saat itu, berita kenaikan iuran tersebut menuai berbagai respon dari masyarakat. Twitter merupakan salah satu media sosial yang digunakan masyarakat dalam menyampaikan aspirasinya. Dari respon tersebut banyak masyarakat yang mendukung kebijakan tersebut dan banyak pula yang menolak kebijakan tersebut. Dan issue dari kenaikan tarif BPJS ini juga diduga berdampak pada subsektor saham kesehatan.

Analisis Sentimen merupakah cabang dari penelitian text mining dan bertujuan untuk mengekstrak atribut dari sebuah komentar (opini, sentimen, dan emosi) yang diekspresikan secara tekstual. Analisis ini dilakukan untuk melihat pendapat atau kecenderungan opini terhadap sebuah masalah atau objek oleh seseorang, apakah cenderung positif, negatif atau netral. 
Analisis sentimen tentang respon masyarakat di sosial media Twitter telah banyak diteliti di berbagai negara. Selain itu ada juga yang meneliti tentang dampak dari respon twitter tersebut terhadap harga saham ataupun nilai tukar. Penelitian yang dilakukan Ranco, dkk (2015) dengan metode korelasi pearson dan Granger causality menunjukkan bahwa terdapat hubungan yang signifikan antara respon twitter dengan harga saham namun nilainya cukup kecil. Hal itu juga sejalan dengan penelitian Nisar(2018) namun pada penelitiannya hubungan tersebut tidak signifikan ${ }^{\left[{ }^{[8]}\right.}$ Penelitian lain oleh Sul Hong, dkk(2016) juga memberikan kesimpulan bahwa sentimen dalam media sosial dapat memprediksi stock return di masa yang akan datang. ${ }^{[13]}$ Penelitian Hong,dkk(2016) juga sejalan dengan Shi, Yong (2018) yang menghasilkan bahwa dengan menggunakan text mining, didapatkan sentimen investor memiliki efek positif pada jangka panjang dan sebaliknya pada jangka menengah. ${ }^{[12]}$

Penelitian lain yang berjudul " A Text Mining Aplication on Monthly Price Development Report" oleh Hatice Burcu Eskici(2018) yang bertujuan menganalisis monthly price development report (MDPR) dari Central Bank of Republic Turki (CBRT) menyimpulkan bahwa kata atau group kata yang sering digunakan mampu merepresentasikan pengukuran inti dari inflasi serta beberapa sektor lain seperti perhotelan dan akomodasi. Selain itu, penggunaan trend, seasonality dan clustering MDPRs lebih signifikan dibandingkan yang hanya menggunakan trend dan seasonality saja untuk menggambarkan IHK tahunan. ${ }^{[6]}$ Selain untuk memprediksi nilai saham dan IHK, analisis sentimen juga digunakan oleh Serda dan Kursad(2014) untuk mengidentifikasi, menyelidiki, dan mengevaluasi kinerja pergerakan nilai tukar US Dollar/Turkish Lira. Penelitian tersebut menyimpulkan bahwa terdapat hubungan yang signifikan antara sentimen twitter dan gerakan nilai tukar USD/TRY. ${ }^{[11]}$

Penelitian ini berisi tentang analisis respon masyarakat di twitter terhadap kenaikan tarif BPJS. Disamping itu, pada penelitian ini juga akan dianalisis apakah sentimen masyarakat tersebut berpengaruh terhadap harga saham kesehatan dengan analisis regresi logistik biner. Dengan adanya penelitian ini, diharapkan bisa menjadi pertimbangan pemerintah dalam menentukan kebijakan kenaikan tarif BPJS.

\section{METODE PENELITIAN}

Penelitian ini dilakukan hanya khusus untuk data Twitter di Indonesia dan khusus untuk wacana kenaikan BPJS yang kabarnya mulai beredar tanggal 13 Agustus 2019. Twitter adalah layanan jejaring sosial dan mikroblog daring yang memungkinkan penggunanya untuk mengirim dan membaca pesan berbasis teks hingga 140 karakter akan tetapi pada tanggal 07 November 2017 bertambah hingga 280 karakter yang dikenal dengan sebutan kicauan (tweet). ${ }^{[5]}$ Periode yang digunakan pada penelitian ini yaitu sejak tanggal 13 Agustus 2019 hingga 13 September 2019. Selain data twitter, penelitian ini juga menggunakan data harga saham Indo Farma dan Kimia Farma yang digunakan untuk analisis lanjutan. Saham merupakan tanda penyertaan modal atas kepemilikan suatu perusahaan (Dewi dkk, 2018). Terdapat banyak saham di sektor kesehatan seperti Kalbe Farma Tbk (KLBF), Kimia Farma (KAEF), Mitra Keluarga Karyasehat Tbk (MIKA), Siloan International Hospitals Tbk(SILO), Medikaloka Hermina (HEAL), Sarana Meditama Metropolitan (SAME), Indofarma(INAF), d1l. ${ }^{[3]}$

Gambar 1 berikut merupakan skema tahapan penelitian :

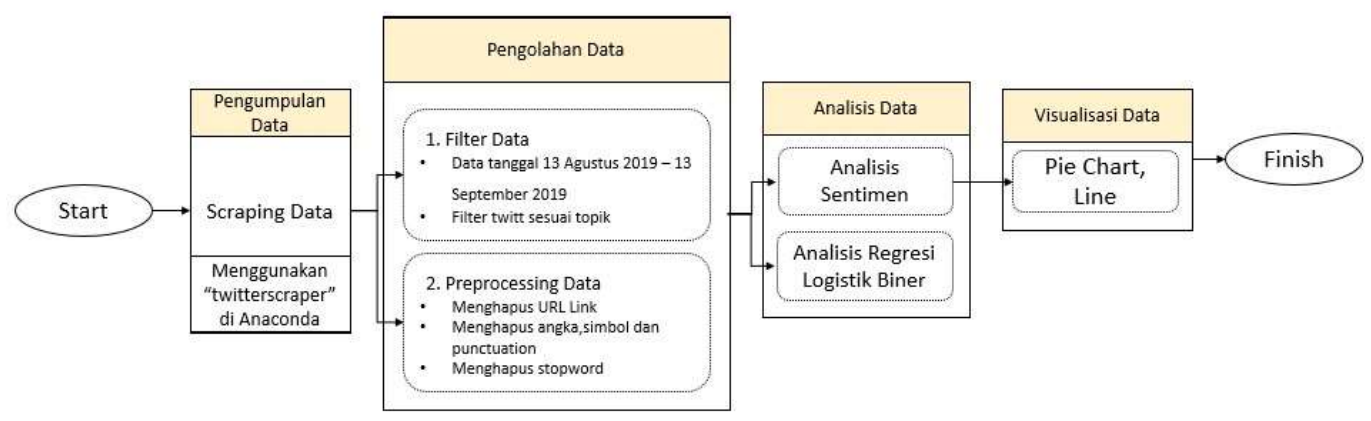

Gambar 1. Skema Alur Penelitian

Data twitter diperoleh dengan metode webscraping dengan bantuan aplikasi Anaconda dan menggunakan alat twitterscraper dengan kata kunci BPJS. Sedangkan untuk data harga saham diperoleh dari web BEI. Kedua data dikumpulkan dengan rentang waktu 12 Agustus 2019 hingga 12 September 2019. Data twitter yang dikumpulkan sebanyak 39262. Data twitter yang telah diperoleh selanjutnya akan diolah dengan aplikasi orange untuk dilakukan filter data dan preprocessing text. Data yang telah dikumpulkan sebanyak 39262. Selanjutnya data difilter untuk diambil yang memiliki sentiment positif dan negatif saja. Sehingga data

IJAIDM Vol. 2, No. 2, September 2019: $1-8$ 
yang siap untuk dianalisis sentimen sebanyak 1556. Analisis Sentimen merupakah cabang dari penelitian text mining dan bertujuan untuk mengekstrak atribut dari sebuah komentar (opini, sentimen, dan emosi) yang diekspresikan secara tekstual. Analisis ini dilakukan untuk melihat pendapat atau kecenderungan opini terhadap sebuah masalah atau objek oleh seseorang, apakah cenderung positif, negatif atau netral. ${ }^{[9]}$

Analisis yang digunakan adalah analisis deskriptif dan analisis inferensia. Analisis deskriptif adalah analisis sentimen yang disajikan dengan Pie Chart dan Line Chart sedangkan analisis inferensia menggunakan analisis regresi logistik biner yang digunakan untuk melihat hubungan respon masyarakat terhadap kenaikan BPJS dengan harga saham kesehatan.

Analisis Regresi Logistik adalah suatu metode analisis statistika untuk mendeskripsikan hubungan antara variabel terikat yang memiliki dua kategori atau lebih dengan satu atau lebih peubah bebas berskala kategori atau kontinu. ${ }^{[1]}$ Adapun regresi logistik dapat dibagi menjadi regresi logistik biner, regresi logistik multinomial dan regresi logistik ordinal. Model regresi logistik biner digunakan untuk menganalisis hubungan antara satu variabel respon dan beberapa variabel prediktor jika variabel responnya menghasilkan dua kategori bernilai 0 dan 1. Bentuk umum model regresi logistik:

$$
(x)=\frac{\exp \left(\beta_{0}+\beta_{1} x_{1}+\cdots+\beta_{p} x_{p}\right)}{1+\exp \left(\beta_{0}+\beta_{1} X_{1}+\cdots+\beta_{p} X_{p}\right)}
$$

Nilai $(x)$ merupakan peluang kejadian sukses dengan variabel bebas $x$ sebanyak $p$. $(x)$ merupakan fungsi non linier sehingga perlu dilakukan transformasi logit agar dapat diperoleh fungsi linier yang berguna untuk melihat hubungan antara variabel bebas dan variabel terikat. Berikut ini merupakan hasil dari transformasi logit:

$$
\ln \left[\frac{\pi(\mathrm{x})}{1-\pi(\mathrm{x})}\right]=\beta_{0}+\beta_{1} \mathrm{X}_{1}+\cdots+\beta_{\mathrm{p}} \mathrm{X}_{\mathrm{p}}
$$

Pada analisis regresi logistik biner terdapat uji yang harus dilakukan, yaitu sebagai berikut :

a) Uji Serentak

Uji serentak atau spasial digunakan untuk mengetahui signifikansi variabel independen terhadap variabel respon secara keseluruhan. Hipotesis yang digunakan:

$$
\begin{aligned}
& H_{0}: \beta_{1}=\beta_{2}=\cdots=\beta_{p}=0 \\
& H_{1}: \text { minimal ada satu } \beta_{i} \neq 0
\end{aligned}
$$

$$
\text { Statistik Uji : G }=-2 \ln \left[\frac{\left(\frac{n_{1}}{n}\right)^{n_{i}}\left(\frac{n_{0}}{n}\right)^{n 0}}{\prod_{i}^{n} \widehat{\pi}_{l}\left(1-\widehat{\pi_{l}}\right)^{1-y_{i}}}\right]
$$

b) Uji Parsial

Uji Parsial merupakan pengujian secara individual apakah suatu variabel prediktor masuk ke dalam model atau tidak. Hipotesis yang digunakan adalah:

$$
\begin{aligned}
& H_{0}: \beta_{i}=0 \\
& H_{1}: \beta_{i} \neq 0
\end{aligned}
$$

$$
\text { Statistik Uji : W }=\frac{\widehat{B_{l}}}{S E\left(\widehat{B_{l}}\right)}
$$

c) Uji Kesesuaian Model

Uji ini digunakan untuk melihat apakah model sudah sesuai untuk digunakan. Pengujian menggunakan Uji Hosmer and Lemeshow dengan Hipotesis sebagai berikut:

$H_{0}$ : Model telah cukup mampu menjelaskan data atau sesuai

$H_{1}$ : Model tidak cukup mampu menjelaskan data 


\section{HASIL DAN PEMBAHASAN}

3.1. Gambaran Umum Sentimen di Twitter Terhadap Kenaikan BPJS dan Harga Saham Kesehatan

Rencana kenaikan BPJS pertama kali diumumkan pada Hari Selasa, 13 Agustus 2019. Rencana itu diumumkan oleh Dewan Jaminan Sosial (DJSN). Sejak saat itu, berita kenaikan iuran tersebut menuai berbagai respon dari masyarakat, baik respon yang mendukung maupun respon yang kontra. Twitter merupakan salah satu media sosial yang digunakan masyarakat dalam menyampaikan aspirasinya. Dari respon tersebut banyak masyarakat yang mendukung kebijakan tersebut dan banyak pula yang menolak kebijakan tersebut. Berikut merupakan beberapa contoh dari respon masyarakat:

Tabel 1. Contoh Sentimen Positif dan Negatif BPJS

\begin{tabular}{|c|c|c|}
\hline $\begin{array}{c}\text { Jenis } \\
\text { Sentimen }\end{array}$ & Waktu & Tweet \\
\hline Positif & $06 / 09 / 201916.26$ & "Bisa ke rsud free pake bpjs kok" \\
\hline Positif & $12 / 09 / 201914.26$ & "Mbak mbak bpjs top iki. Gercep" \\
\hline Positif & $15 / 08 / 201913.05$ & $\begin{array}{l}\text { "Temen aku pake BPJS terus mba, sudah } \\
\text { beberapa kali ESWL free kok." }\end{array}$ \\
\hline Negatif & $03 / 09 / 201914.54$ & $\begin{array}{l}\text { "Emak emak siapkan panci buat nampolin debt } \\
\text { colector BPJS" } \\
\text { "Yg bayar rutin aja kadang ngak bs make }\end{array}$ \\
\hline Negatif & $31 / 08 / 201911.00$ & $\begin{array}{l}\text { fasilitas BPJS.." } \\
\text { "gmn bs mau kuliah, nunggak bpjs aja gak bs }\end{array}$ \\
\hline Negatif & $09 / 09 / 201922.40$ & sekolah“ \\
\hline
\end{tabular}

Dari contoh beberapa tweet di atas, menunjukkan bahwa sentimen yang negatif menunjukkan bahwa program BPJS kurang memberikan pelayanan yang baik dan mengalami masalah terkait dengan biaya. Sedangkan untuk yang positif menunjukkan bahwa dengan menggunakan BPJS biaya perawatan kesehatan gratis.

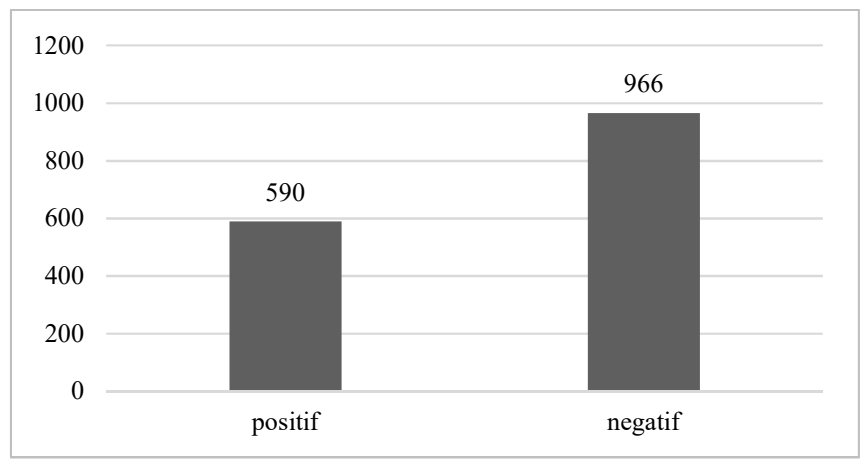

Gambar 2. Frekuensi Harian Sentimen Masyarakat di Twitter 13 Agustus 2019-12 September 2019

Hasil pengolahan analisis sentimen yang telah digambarkan oleh Gambar 2 menunjukkan bahwa 966 tweet masyarakat di twitter beropini negatif terhadap masalah BPJS sejak diumumkan berita kenaikannya. Hal ini menunjukkan bahwa rencana kenaikan BPJS dipandang masyarakat sebagai hal yang negatif dan merugikan masyarakat.

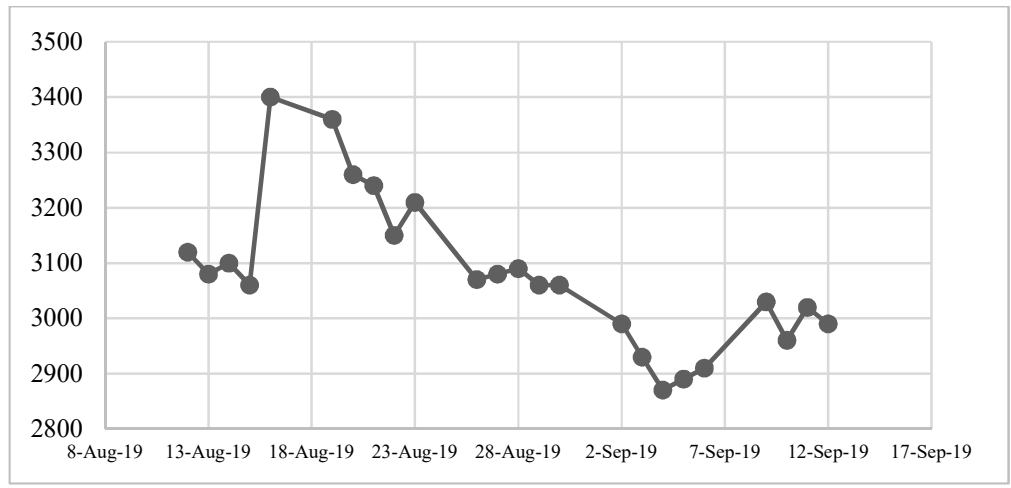

Gambar 3. Grafik Harga Saham Kimia Farma 12 Agustus 2019 - 12 September 2019

IJAIDM Vol. 2, No. 2, September 2019: $1-8$ 


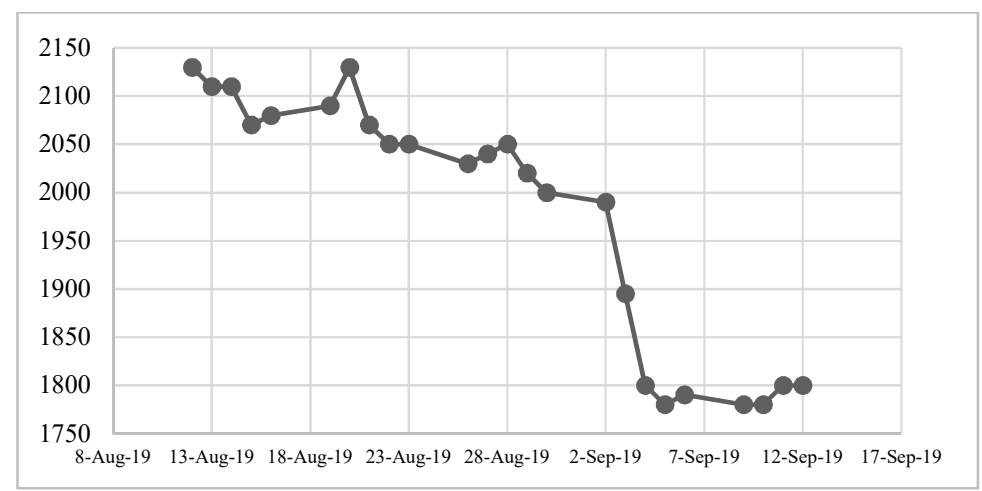

Gambar 4. Grafik Harga Saham Indo Farma 12 Agustus 2019 - 12 September 2019

Selain melihat sentimen masyarakat di Twitter terhadap kenaikan BPJS, penelitian ini juga melihat efek dari sentimen tersebut terhadap indeks harga saham di bidang kesehatan. Pada penelitian ini digunakan dua saham kesehatan yaitu Kimia Farma dan Indo Farma. Kedua perusahaan ini merupakan perusahaan milik BUMN, yang mana jika BPJS naik maka diduga dampak besarnya juga ke kedua saham tersebut. Kedua Grafik diatas merupakan grafik dari harga saham Kimia Farma dan Indo Farma dari tanggal 12 Agustus 2019 hingga 12 September 2019. Jika dilihat dari trend nya,harga saham Kimia Farma mengalami fluktuatif selama satu bulan, akan tetapi lebih cenderung membentuk trend negatif.

Sama halnya dengan harga saham Kimia Farma yang cenderung negatif, harga saham Perusahaan Indo Farma juga mengalami trend yang menurun selama satu bulan. Namun saham Indo Farma ini cenderung lebih besar penurunannya dibanding Kimia Farma. Pada 12 Agustus 2019, harga saham Indo Farma sebesar 2125 dan pada 12 September 2019 harga saham sebesar 1800. Penurunan sebesar 325 ini lebih besar jika dibandingkan dengan penurunan harga saham Kalbe Farma yang hanya sebesar 125.

\subsection{Pemodelan Efek Sentimen Terhadap Harga Saham KAEF dan INAF}

Untuk melihat apakah terdapat efek sentimen terhadap harga saham bidang kesehatan digunakan pemodelan dengan menggunakan Regresi Logitik Biner. Harga Saham yang digunakan Saham KAEF dan Saham INAF. Model yang terbentuk adalah sebagai berikut:

Tabel 2. Model Hubungan Sentimen Terhadap Harga Saham KAEF dan INAF

\begin{tabular}{cc}
\hline Saham & Model \\
\hline KAEF & $\ln \left(\frac{\pi_{i}}{1-\pi_{i}}\right)=2,8+0,028$ Positif -0.103 Negatif $^{* *}$ \\
INAF & $\ln \left(\frac{\pi_{i}}{1-\pi_{i}}\right)=3,514-0.023$ Positif -0.094 Negatif \\
\hline
\end{tabular}

Tabel 3. Hasil Uji Omnibus dan Hosmer Lemeshow Saham KAEF dan INAF

\begin{tabular}{cccc}
\hline Model & Pengujian & Signifikansi & Keputusan \\
\hline KAEF & $\begin{array}{c}\text { Omnibus } \\
\text { Hosmer and } \\
\text { Lemeshow }\end{array}$ & 0,123 & Gagal Tolak Ho \\
& Omnibus & 0,861 & Gagal Tolak Ho \\
& Hosmer and & 0,123 & Gagal Tolak Ho \\
INAF & Lemeshow & 0,189 & Gagal Tolak Ho \\
& & & \\
\hline
\end{tabular}

Tabel 2 di atas merupakan hasil dari pemodelan efek sentimen terhadap harga saham KAEF dan INAF. Sedangkan Tabel 3 menunjukkan apakah variabel independen signifikan mempengaruhi harga saham secara spasial dan untuk mengetahui kecocokan model. Hasil dari uji tersebut menyebutkan baik model saham KAEF maupun INAF model yang terbentuk adalah fit. Sedangkan Hasil uji omnibus menghasilkan bahwa variabel independen tidak memengaruhi secara spasial.

Dari persamaan Saham KAEF diatas bisa diketahui bahwa ketika sentimen positif bertambah satu maka kecenderungan nilai saham untuk naik adalah sebesar 1,029. Sedangkan untuk sentimen negatif, apabila bertambah satu sentimen negatif maka kecenderungan nilai saham untuk naik adalah sebesar 0,902. Hasil ini menunjukkan bahwa jika sentimen atau respon masyarakat positif maka harga saham KAEF lebih cenderung 
untuk naik akan tetapi tidak siginifikan secara statistik, sedangkan jika respon negatif maka harga saham akan cenderung tidak naik dan siginifikan di alfa 10 persen.

Hasil yang berbeda ditunjukkan oleh model Saham INAF. Dari persamaan diatas bisa diketahui bahwa ketika sentimen positif bertambah satu maka kecenderungan nilai saham INAF untuk naik adalah sebesar 0,977. Kecenderungan ini tidak jauh berbeda jika dibandingkan dengan sentimen yang negatif, yaitu ketika sentimen negatif bertambah satu maka kecenderungan nilai saham untuk tidak naik adalah sebesar 0,910.

Tabel 4. Ketepatan Klasifikasi Model Saham KAEF

\begin{tabular}{ccccc}
\hline & & Prediksi & \multirow{2}{*}{ Percentage Correct } \\
\cline { 3 - 4 } & & Naik & Tidak Naik & \\
\hline \multirow{2}{*}{ Observasi } & 13 & 2 & 86,7 \\
& Naik & 5 & 3 & 37,5 \\
\hline & Tidak Naik & Overall Percentage & 69,6 \\
\hline
\end{tabular}

Tabel 5. Ketepatan Klasifikasi Model Saham INAF

\begin{tabular}{ccccc}
\hline & & \multicolumn{2}{c}{ Prediksi } & Percentage Correct \\
\cline { 3 - 4 } & & Naik & Tidak Naik & \\
\hline Observasi & Naik & 4 & 2 & 87,5 \\
& Tidak Naik & 4 & 3 & 42,9 \\
\hline \multicolumn{3}{c}{ Overall Percentage } & 73,9 \\
\hline
\end{tabular}

Tabel 4 dan Tabel 5 menunjukkan hasil ketepatan model. Hasilnya adalah prediksi model saham KAEF sebesar $69,6 \%$ dan untuk prediksi model saham INAF sebsar 73,9\%. Kedua nilai ini menunjukkan bahwa model cukup sesuai. Hasil pemodelan di atas menunjukkan perbedaan antara Saham KAEF dan INAF. Hal ini mungkin dikarenakan pada sisi fundamental KAEF lebih bagus sehingga selalu mendapatkan keuntungan. Sedangkan pada saham INAF selalu mengalami kerugian. Hal ini tentu bisa menjadi pertimbangan investor dalam menginvestasikan sahamnya.

\section{KESIMPULAN}

Berdasarkan hasil dan pembahasan dalam penelitian ini, respon terhadap isu kenaikan biaya BPJS didominasi oleh respon negative. Berdasarkan dominasi muatan dari cuitan yang merespon negative, mereka menyoroti bahwa program BPJS selama ini kurang memberikan pelayanan yang baik dan mengalami masalah terkait dengan biaya. Sebaliknya muatan dalam respon positif sebagian besar menyatakan bahwa BPJS bermanfaat dikarenakan biaya perawatan kesehatan menjadi gratis. Secara statistik, respon masyarakat terhadap kenaikan biaya BPJS berpengaruh secara signifikan terhadap harga saham BUMN Kimia Farma (KAEF), namun tidak siginifikan memengaruhi harga saham BUMN Indofarma (INAF). Kesimpulan ini diperoleh berdasarkan hasil model regresi logistik yang memiliki tingkat akurasi 69,6 persen dan 73,9 persen.

\section{REFERENSI}

[1] Agresti, Alan. Categorical Data Analysis. New York: Inc. John Wiley and Sons.2002.

[2] Badan Penyelenggara Jaminan Sosial, BPJS Kesehatan, diakses pada Agustus 2019.

[3] Dewi, Gusti Ayu,dan Diota P V. Investasi dan Pasar Modal Indonesia. Depok: PT Rajagrafindo Persada.2018.

[4] Ervita Kusuma Putri, T. S. "Penerapan Text Mining Pada Sistem Klasifikasi Email Spam Menggunakan Naïve Bayes”. Jurnal Sarjana Teknik Informatika. 2014;2(3).

[5] Hadi, Mulya. Twitter untuk Orang Awam. Palembang: Maxikom.2010.

[6] Hatice Burcu Eskici, N. A. A Text Mining Aplication on Monthly Price Developments Report. Research and Monetary Policy Departement.2018;18(2):51-60.

[7] Jiawei Han, M.K. Data Mining Concepts and Tchinique third edition. Waltam:Elxevier.2012.

[8] Nisar, Tahir M, Man Yeung. Twitter as a tool for forecasting stock market movements: A short-window event study. The Journal of Finance and Data Science. 2018;4(2):101-119.

[9] Pang, B., \& Lee, L. Opinion mining and sentiment analysis. Foundations and trends in information retrieval. 2008; 2(1-2):1-135.

[10] Ranco G, Aleksovski D, Caldarelli G, Grčar M, Mozetič I. The Effects of Twitter Sentiment on Stock Price Returns. PLoS ONE. 2015;10(9).

[11] Serda Selin Ozturk \& Kursad Ciftci."A Sentiment Analysis of Twitter Content as a Predictor of Exchange Rate Movements," Review of Economic Analysis, Rimini Centre for Economic Analysis.2014 ;6(2):132140.

IJAIDM Vol. 2, No. 2, September 2019: $1-8$ 
[12] Shi, Yong \& TANG, Ye-ran \& CUI, Ling-xiao \& Long, Wen. A Text Mining Based Study of Investor Sentiment and Its Influence on Stock Returns. Economic Computation And Economic Cybernetics Studies And Research. 2018;52: 183-199.

[13] Sul, Hong \& Dennis, Alan \& Yuan, Lingyao. Trading on Twitter: Using Social Media Sentiment to Predict Stock Returns: Trading on Twitter. Decision Sciences.2017;48(3):454-488.

[14] Windu Gata, P. Akurasi Text Mining Menggunakan Algoritma K-Nearest Neighbour pada Data Content Berita SMS. Jurnal Format. 2016;6(2).

\section{BIBLIOGRAFI PENULIS}

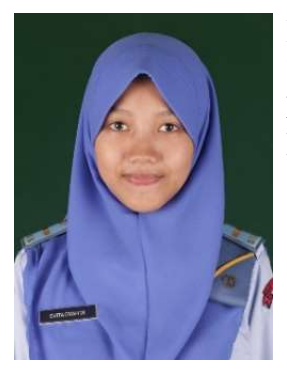

Evita Dyah Wardhani lahir di Blitar, 11 Agustus 1997. Lulus dari SDN Sananwetan 3 pada Tahun 2010, melanjutkan ke SMPN 1 Blitar dan lulus tahun 2013. Setelah itu melanjutkan ke SMAN 1 Blitar hingga lulus tahun 2015. Saat ini sedang menempuh pendidikan D-IV Politeknik Statistika STIS di Jurusan Statistik.

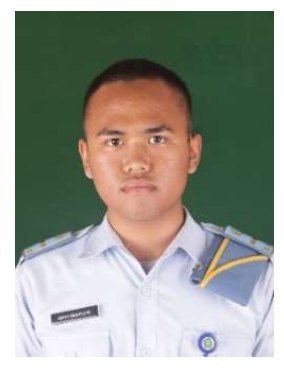

Arya Wahyu Nugroho lahir di Semarang, 22 Oktober 1998. Lulus SDN Kartini 01 pada tahun 2010, melanjutkan ke SMPN 39 Semarang dan lulus tahun 2013. Setelah itu melanjutkan ke SMAN 3 Semarang hingga lulus tahun 2016. Menempuh pendidikan DIV Statistik di Politeknik Statistika STIS hingga saat ini

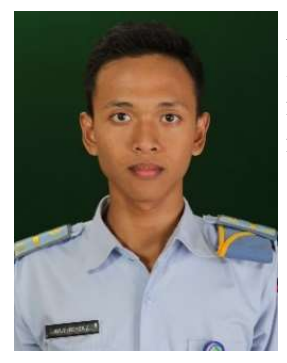

Ayufi Reyza Zakaria lahir di Banyuwangi, 1 April 1998, Lulus dari SDN Kepatihan tahun 2010, melanjutkan ke SMPN 1 BANYUWANGI dan lulus tahun 2013. Setelah itu melanjutkan ke SMAN 1 Glagah Banyuwangi dan lulus pada tahun 2016. Saat ini sedang menjalani pendidikan DIV-Statistik Ekonomi di Politeknik Statistika STIS.

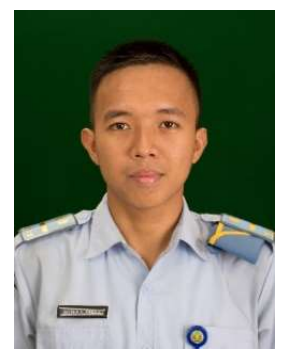

Satria Kurnia Areka lahir di Bengkulu, 01 September 1998. lulus dari SDN 74 Kota Bengkulu pada tahun 2010, melanjutkan ke SMPN 5 Kota Bengkulu dan lulus pada tahun 2013. Setelah itu melanjutkan ke SMAN 5 Kota Bengkulu dan lulus pada tahun 2016. Sekarang menempuh pendidikan D-IV Statistika di Politeknik Statistika STIS

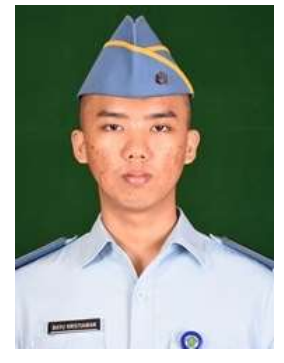

Arya Damar Prakasa lahir di Tanggerang, 11 Juni 1998, Lulus dari SDN 1 Sukajadi pada Tahun 2010, melanjutkan ke SMPN 51 Palembang dan lulus tahun 2013. Setelah itu melanjutkan ke SMA Negeri 3 Palembang dan lulus pada tahun 2016. Saat ini sedang menjalani pendidikan DIV- Statistik Ekonomi di Politeknik Statistika STIS. 


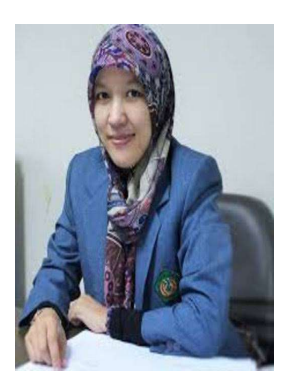

Rani Nooraeni , lulusan Sekolah Tinggi Ilmu Statistik (STIS) Badan Pusat Statistik (BPS), Jakarta. Memperoleh Gelar M.Stat di Univeristas Padjajaran dan bekerja di BPS sejak awal tahun 2007. Setelah itu ditugaskan di Politeknik Statistika STIS mulai tahun 2015 hingga sekarang. 